\title{
Vor- und Dankwort
}

Bei dieser Arbeit handelt es sich um eine überarbeitete Fassung der an der Heinrich-Heine-Universität Düsseldorf eingereichten Dissertation.

Eine solche Arbeit könnte ohne Unterstützung nicht realisiert werden. Mein ganz besonderer Dank gilt Frau Prof. Dr. Dagmar Börner-Klein, die bei mir das Interesse für dieses Thema geweckt hat und mir stets mit hilfreichen Anregungen und ihrer fürsorglichen Betreuung zur Seite stand.

Ebenfalls herzlich danken möchte ich Frau Prof. Dr. Regina Grundmann für ihre wertvollen und konstruktiven Ratschläge.

Besonders danken möchte ich auch der Gerda Henkel Stiftung, die mir durch ihre großzügige Förderung diese Arbeit ermöglichte.

Den Herausgebern danke ich dafür, dass sie meine Arbeit in ihre Reihe aufgenommen haben. Ein herzlicher Dank gilt auch der Lektorin, die mir in der letzten Phase unterstützend zur Seite stand.

Nicht zuletzt möchte ich auch meiner Familie einen Dank aussprechen: Meinen Eltern, die stets ein offenes Ohr für mich hatten, und meiner Schwester, die mir in zahlreichen Momenten mit hilfreichen Anregungen zur Seite stand.

Mein ganz besonderer Dank gilt Thomas - für die unzähligen Seiten, die er Korrektur gelesen hat, für seine Geduld und seine Fürsprache - letztendlich für alles. 
